\title{
Perceptions of Successful Veterinary School Applicants: Assessment Data to Improve Student Success
}

\author{
Elizabeth Whitt, Danny Walker, Diana Watson, Jason Roberts, Joey Mehlhorn \\ University of Tennessee at Martin, USA
}

Received: September 22, 2021 Accepted: October 19, 2021 Published: November 3, 2021

doi:10.5296/jas.v9i4.19038

URL: https://doi.org/10.5296/jas.v9i4.19038

\begin{abstract}
Admission to colleges of veterinary medicine has become increasingly more competitive through the years. The increased number of applicants require students and the programs they are attending to help students distinguish themselves in the applicant pool. Many students understand the importance of the science related coursework early on in their undergraduate career. The soft skills along with mentoring have been shown to be important for applicant success. Time management skills can be some of the most vital skills for undergraduate students to practice before matriculation to veterinary school. In addition, group skills and conflict resolution are perceived as important among veterinary alumni and students. Mentoring is critical throughout the education process. The personal aspects and professional guidance given by professors make for the most successful advising of undergraduate pre-veterinary students. Results indicated that students could benefit from communication skills being included throughout the curriculum, especially in context of veterinary science courses.
\end{abstract}

Keywords: student success, graduate application, student preparation

\section{Introduction}

Bachelor of science programs in pre-veterinary medicine continue to be a large area of interest for college students. These programs appeal to students who have a passion for science, medicine and working with animals. Programs attract many undergraduate freshmen, however, the percentage of applicants accepted to colleges of veterinary medicine (CVM) is often much lower. While these programs can be expensive to operate and require specialized laboratory facilities and animals, they provide a unique learning opportunity for students wanting to pursue a veterinary career. There is a need for program development that leads to student success with one outcome measure being the number of students matriculating to a CVM. It is important to note that student acceptance to post graduate work is not the only measure of program success. Undergraduate pre-veterinary programs 
lead to well-rounded graduates who have a strong understanding of animal agriculture and are ready for transition to industry jobs upon undergraduate graduation. This is important given that many students who start college a pre-veterinary major choose either to not apply for CVM admission or change majors along the way. University faculty must have a clear direction on what the program outcomes should be and develop a plan to reach those outcomes. Programs must actively assess and improve their preparation of students to put forward more competitive CVM applicants.

\section{Literature Review}

Matriculation into colleges of veterinary medicine is a continually evolving process that requires students and mentors to be flexible within their guidance of the process. The application process begins through the Association of American Veterinary Medical Colleges (AAVMC) with the Veterinary Medical College Application Service (VMCAS) application. The VMCAS or Veterinary Medical College Application Service allows students the choice of sending their application to the Colleges of Veterinary Medicine within the United States, Canada, as well as International Programs. This is the initial impression that a CVM will have on the applicants, followed by interviews and/or supplemental applications. These two sections, the VMCAS written application along with the interview portion, are the factors evaluated to allow a student's matriculation into a CVM. Studies have shown that predicting student success can be forecast early by looking at factors other than student grades (Green et al., 2006; Holladay et al., 2020).

The AAVMC website contains beneficial information on the importance of mentoring as well as veterinary experience needed for successful application to a college of veterinary medicine. Advice on researching schools as well as sample recommendation letters and transcript verification processes allow potential applicants to be prepared for the application process (AAVMC Webpage, 2020). Mentorship and advising through an academic professor are what helps to guide pre-veterinary students on the track of successful admission into veterinary schools. Within the first two years of undergraduate coursework, the AAVMC encourages students to meet with their academic advisor to go over required coursework for applying to a CVM, but also begin preparing for future opportunities to enhance their application (VMSAR, 2020). The summers between undergraduate semesters are suggested to be filled with gaining veterinary experience the AAVMC requires students to have. A veterinary science advisor guides students on the requirements and opportunities to gain the required experiences needed to be competitive. The importance of advising cannot be overlooked in the academic process. Advisors can help potential students with career exploration and provide guidance in the steps needed for successful application and persistence in the field of study (Trivedi, Clark, and Todd See, 2021; Crowe, 2020). Advisors write recommendation letters for internships that add additional experience to a student's application. The final two years a student spends in their undergraduate career, their mentor is guiding them on choices of veterinary schools, recommendation letters, and final coursework to complete their prerequisites (VMSAR, 2020)

The second area that the AAVMC focuses on for their application process is veterinary 
experience. Within the areas of experience required for the application, veterinary experience is most important. The time spent shadowing veterinarians is what gives applicants their best experience in the field. This applicant section can include any experience a student had under the direct supervision of a veterinarian. Areas can include the clinical aspects in a veterinary hospital, health sciences or agribusiness opportunities. These hours of veterinary experience are either required or highly encouraged for applicants to a CVM (VIN Foundation, 2019).

Lastly, a veterinary school application includes sections for animal experience, research, extracurricular activities and leadership, work experience, and final essays. The collection of these sections in a student's admission to a CVM are what ensure the applicants fit within their program. To finalize their decision, most veterinary schools perform interviews to complete their choice of matriculated students. This is the opportunity where a CVM summarizes the applications and analyzes the final soft skills a university would be interested in. Within a research project by Haldane, it is quoted that "Veterinarians and students ranked verbal communication and interpersonal skills as the most important skill set for an entry level veterinarian" as well as being an area that students "felt they lacked confidence in" (Haldane, Hinchcliff, Mansell, and Baik, 2017). Communication skills are very important in professional life of a veterinarian and the well-functioning of a veterinary team (Kinneson, May, and Guile, 2014; Rauch, Wissing, Tipold, and Klinsorgen, 2021). These interview opportunities allow for CVMs to evaluate these soft skills that a student possesses and makes their matriculation decisions based on these final criteria.

In the veterinary work force, those applying and eventually working in the field have changed from a historically male dominated field to a female dominated field. A recent analysis showed that in 2019, $63 \%$ of veterinarians in the United States are female, and the remaining 37\% are male (Data USA, 2021). These results have moved in this upward trend for the past 5 years alone. In 2014, 57.7\% of female veterinarians in the United States with the remaining $42.3 \%$ being male. The average age of male veterinarians is 51.5 and the average age for female veterinarians is 40.8 (AAVMC Annual Data Report, 2020). The applying and incoming veterinary students are predominately female giving rise to the younger female veterinary population. In 2019, the number of applications to a CVM was 8,645 applications (AAVMC Notes, 2021) with approximately 87\% of those being female (AAVMC Annual Data Report, 2020). Although these numbers can be extremely encouraging to a female applicant, it does show they have majority of applicants to compete against as well. It is common with female applicants to apply with general small animal experience so for these applicants to stand out, it is important that they gain a diversity of veterinary experience.

Within the process of application to a CVM, there are a variety of factors that undergraduate students must understand before embarking on this process. Factors that have already been mentioned here such as faculty mentoring, Grade Point Average (GPA), veterinary and animal experience hours, research time, and supplemental information to strengthen a student's application. These evaluations require an applicant to begin their preparation years in advance along with the aid of academic mentors and veterinarians to walk them through 
this process. These countless hours of work and studying is what gives the weight to a student's matriculation into CVM.

\section{Materials/Methods}

\subsection{Undergraduate Student Population}

The data for this project was collected from two separate population groups consisting of freshman students and alumni who had been accepted to a CVM program. The survey questions focused on student experiences that were helpful for successful veterinary careers. These included important courses and soft skill development among graduates. Historical aggregated class assignment data was collected for undergraduate pre-veterinary students enrolled in the freshman studies general course during Fall 2017 - 2020. Data from the undergraduate freshman students $(n=146)$ was used to develop a baseline for the typical student planning to choose veterinary medicine as a career. The course was comprised solely with pre-veterinary students and was taught by a veterinary science faculty member. Within this course freshman students are given a semesters guide to general undergraduate life as a college student and mentorship to achieve acceptance to a college of veterinary medicine (CVM). The assignment allowed for students to give their initial perceptions about achieving success before they had completed the first semester of college. Factors evaluated included classes, extracurricular activities, internships, job opportunities, and soft skills. Students were also asked about prior experiences in high school including Future Farmers of America FFA and 4-H involvement, dual- enrollment and AP courses, as well as agricultural background. Students chose from a Likert scale of strongly agree to strongly disagree if they believed it was going to be important and/or beneficial for their future. The same survey instrument was completed by alumni for the program who had been accepted or completed a doctorate in Veterinary Medicine.

\subsection{Alumni Population}

To gauge alumni perceptions, a survey $(n=37)$ was developed covering similar questions as the freshman assignment. The survey was built and distributed to the alumni students in Summer 2021 who had been accepted into a CVM program. Alumni matriculated from UT Martin between 2014 and 2021 and majored in animal science or pre-veterinary medicine. The survey was sent out through an online format to allow for ease of accessibility. The survey protocol was approved by the University of Tennessee at Martin Institutional Review Board, Docket Number, 2022-875-E05-4005/Mehl,Joe. The alumni survey followed up similar questions asked to the freshman students, and added which courses, jobs, and skills they believed were the most important to their success in veterinary school or the profession. The survey was specifically distributed to students who completed the undergraduate pre-veterinary program at UT Martin and matriculated to a CVM program. These responses would be representative of students who had completed the freshman studies course and selected veterinary science as a career choice. Alumni survey questions included choice of veterinary school, any other advanced degrees, and current career status. In addition, like the undergraduate survey, the alumni were asked to rank different undergraduate courses and soft skills based on their personal success in the veterinary field from extremely important to not 


\section{Macrothink}

Journal of Agricultural Studies

ISSN 2166-0379

2021, Vol. 9, No. 4

necessary. The alumni survey asked for jobs, internships, and/or extracurriculars participated in to prepare for success in admission to a CVM. The final questions related to perceptions they wished they had known before applying to veterinary schools and ways the process could have been improved. This final question was an open-ended discussion.

\section{Results}

Demographics from both populations were reflective of trends in the profession. Females represented $67 \%$ and $76 \%$ in the undergraduate and alumni responses and is like the national average. Both surveys focused on measuring courses and soft skills, with the alumni survey adding advising.

\subsection{Importance of Academic Courses}

Respondents were given a Likert scale 1-5 with 1 being extremely unimportant and 5 being extremely important. The top three results from the freshman students, the classes rated most important for their career success were Biology, Animal Science, and Chemistry with Communications coming in closely thereafter. The alumni who were surveyed ranked similar courses as the undergraduate students. These included courses in Animal Science, Biology, and Communications. It was not expected that the alumni findings were so similar to the undergraduate responses. The authors were expecting business skills to be on the alumni list since most were practicing veterinarians which typically have to deal with business issues within the practice. A complete listing of rankings are given in figure 1 and 2 below.

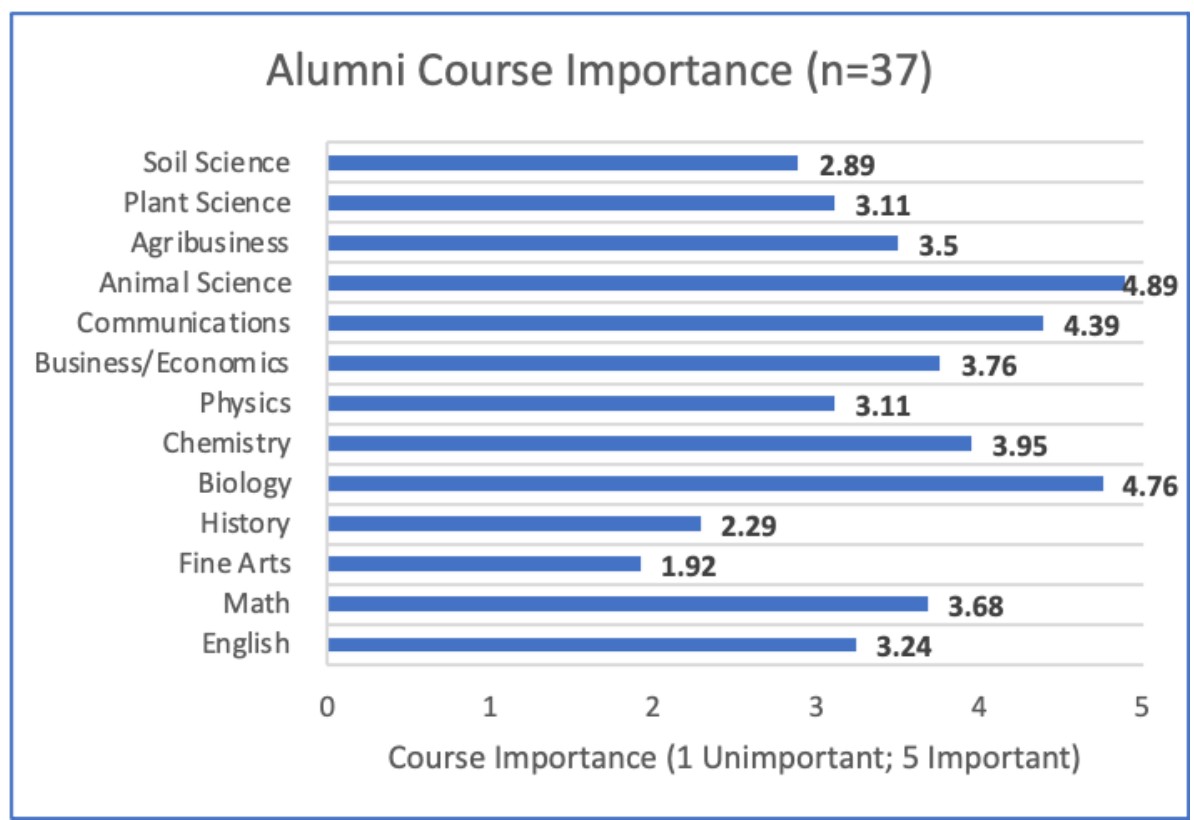

Figure 1. Alumni Course Importance Survey Results 


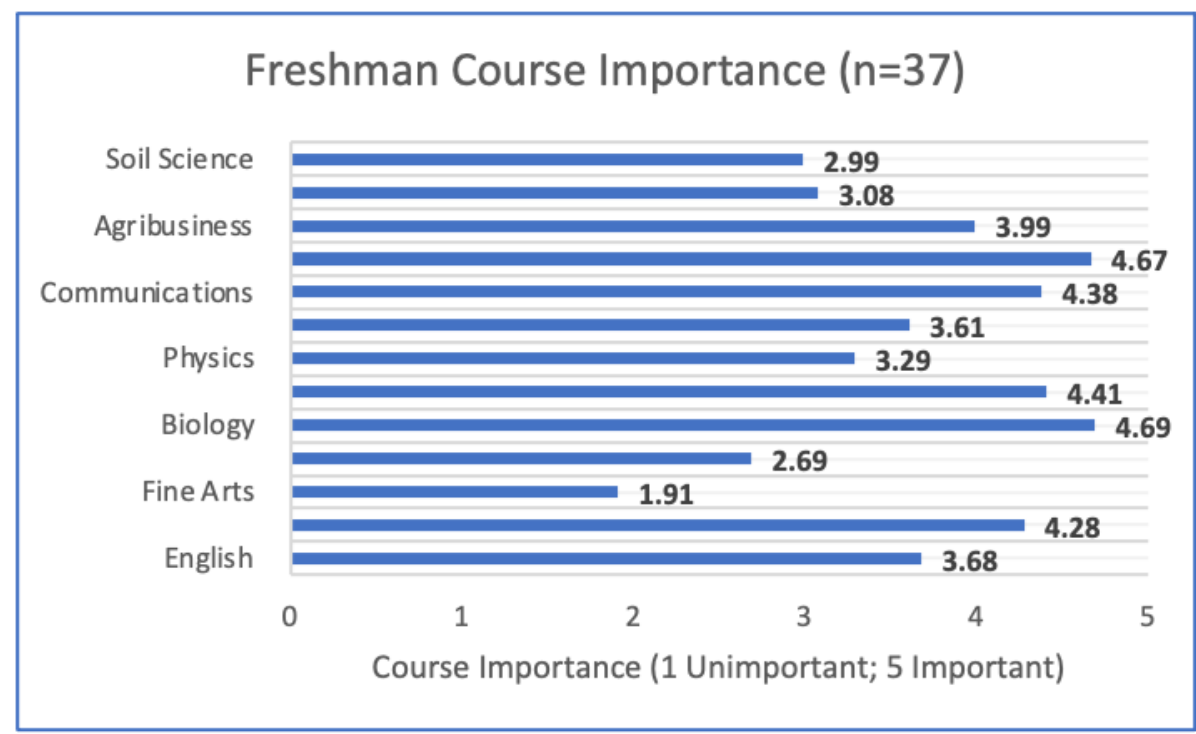

Figure 2. Freshman Course Importance Results

Alumni ranked the animal science, biology, and communications courses as the most important. Thirty-four of those responses indicated that their animal science courses were extremely important to their success in the veterinary field. It could be inferred that alumni felt the animal science courses were not only relatable but contained valuable information to matriculation into a CVM. Classes focused on animal science are a benefit that programs can give students especially if they contain experiential components. Secondly, alumni rated biology courses with 29 reporting they were extremely important. When evaluating the freshman's general studies survey, their top two courses perceived extremely important were animal science and biology. Finally, the third course that 17 alumni chose as extremely important was communications. This varied with the choices of freshman students since the subsequent course freshman perceived would be important for their matriculation to a CVM was chemistry. This course choice was surprising to the authors, since as a pre-veterinary undergraduate student, they only take the single communications course required as a general education credit. The communications class was more important than expected and might indicate a need to incorporate more communication skill development in the program. Alumni and freshman both rated business/economics skills similarly. The business skills are rated important by both groups and are becoming more essential as rising tuition costs require larger commitments of students.

\subsection{Importance of Soft Skills}

Top results from the freshman survey soft skills chosen were time management, conflict resolution, and group skills. In contrast, the three skills freshman students chose as least important for success in the veterinary field were international experience, foreign language skills, and human relation skills. Alumni rated time management, group skills, and conflict resolution as the most important to the success of students in the veterinary field. Group skills and conflict management are both essential for the veterinary profession given the nature of the job. It is apparent that students understand early in the process the importance 


\section{Ml Macrothink}

Journal of Agricultural Studies

ISSN 2166-0379

2021, Vol. 9, No. 4

of these traits. The value of time management skills is covered extensively in the freshman studies course and faculty advisers work to encourage the importance of time management early with students. The first skill of time management is an individualized skill that takes personal discipline to develop, but the following two are group skills that require working in environments with others. Group skills and conflict resolution can be learned in environments such as jobs, school, and extracurriculars, but are difficult to isolate and work on. The use of group projects and internships are good opportunities to develop these skills. To improve the preparedness of students in these skills, it may continually encourage students to get involved in these areas, not only for additions to resumes or experience hours, but to improve on their group and conflict resolution skills. The complete ratings for students and alumni and be see in figure 3 and figure 4 below.

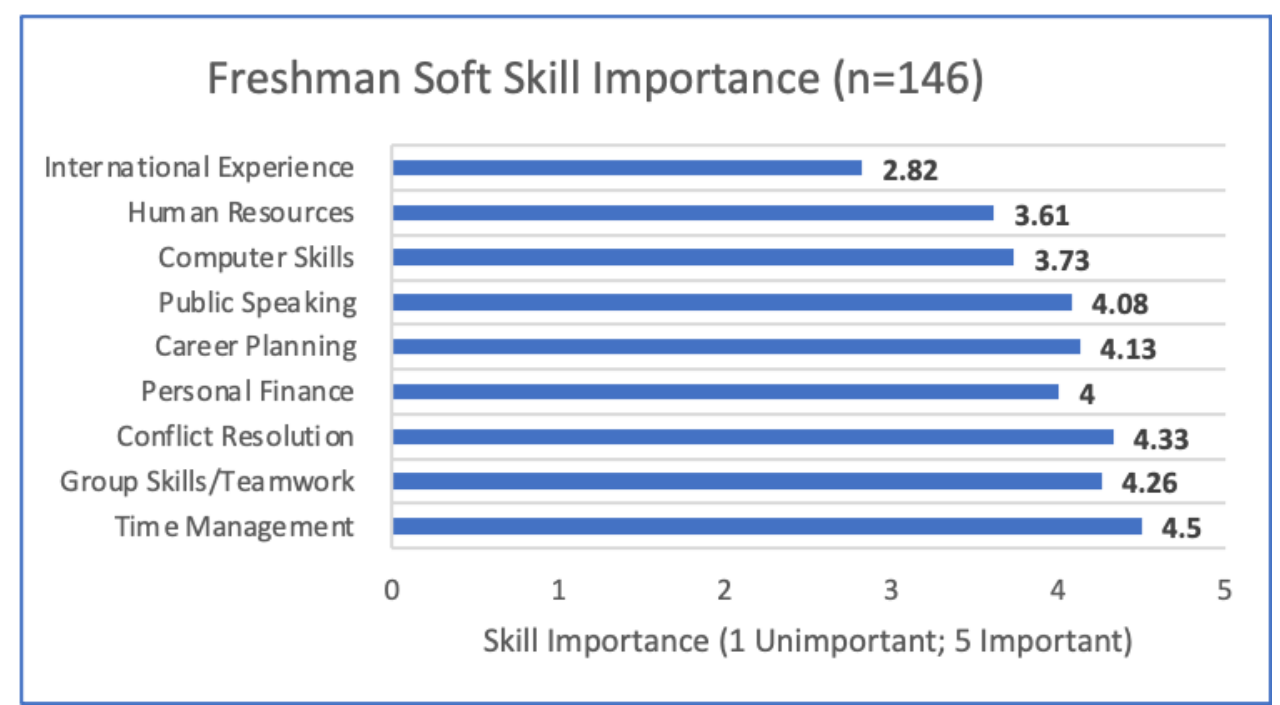

Figure 3. Perceived Importance of Soft Skills to Freshman

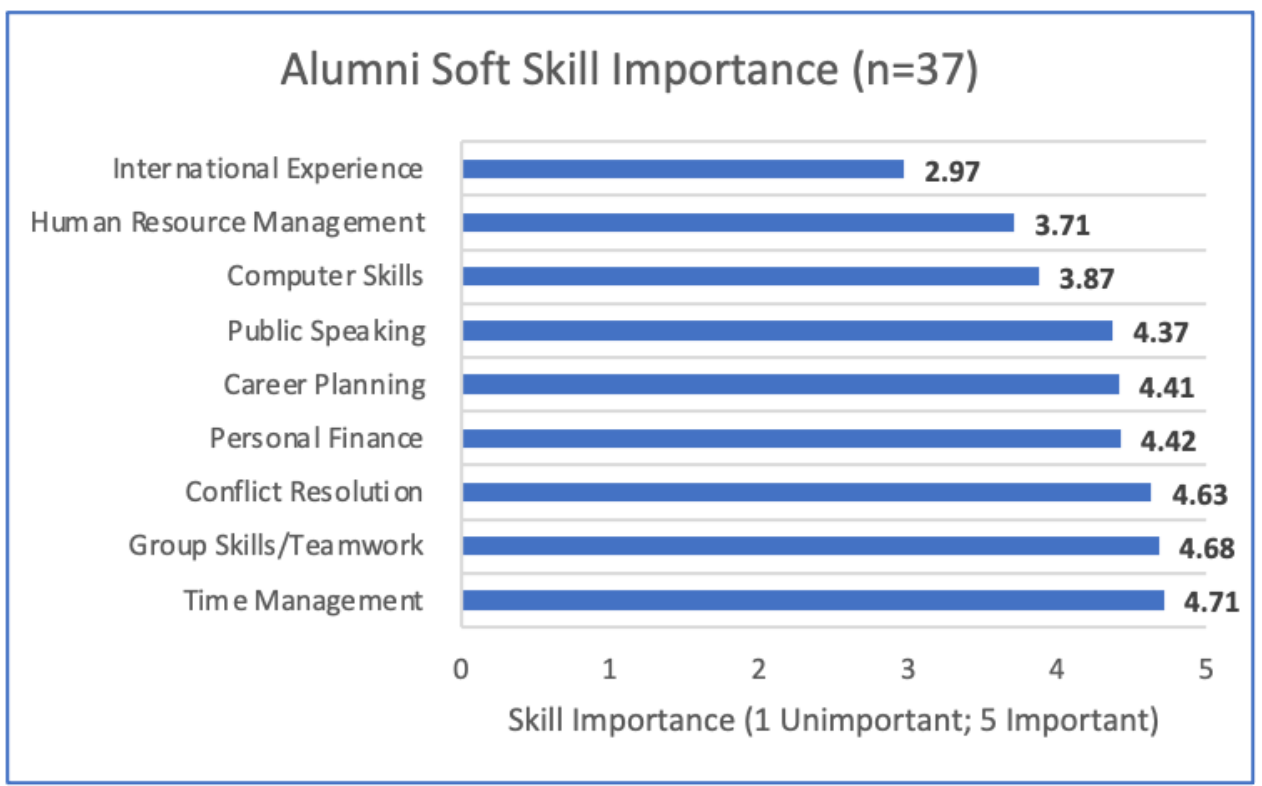

Figure 4. Perceived Importance of Soft Skills to Alumni 


\subsection{Alumni Perceptions on Advising}

An additional section of the survey was added for alumni that asked about importance of advising and mentorship to their veterinary career. Eighty one percent of the responses said that it was "extremely important" for their success in the veterinary career field with the additional responses saying it was "important." Although the undergraduates did not evaluate this question about advising or mentoring, it can be determined that it is a vital portion of their undergraduate career. As with any professional graduate program, having a mentor to guide you through the application process and to prepare you along the way is essential. The faculty time spent mentoring and advising can be time consuming, but given the responses from alumni it does have great value. This is an area that needs to be encouraged on college campuses, but many times it is overshadowed by teaching and scholarly activities. The overwhelming response by successful graduates can lead to the assumption, that academic advising and mentoring should continue to be something focused on strongly as students enter their undergraduate career.

\section{Conclusions}

Soft skills are important to success in any professional field and especially in the veterinary field. Veterinarians deal with the public as well as the staff in the practice. Time management skills can be some of the most vital skills for undergraduate students to practice before matriculation to veterinary school. In addition, group skills and conflict resolution perceived as important among alumni and students.

Results indicate that the majority of incoming undergraduate freshman surveyed have a basic understanding of the important courses and skills required for their future success. The most important skills and courses were closely related in every area evaluated of both the alumni and freshman. The courses rated as most important by alumni and undergraduates were animal science courses. Having the alumni and students rate these courses as most vital to success indicates that the material was essential in preparing students for matriculation into a CVM. In addition, students and alumni indicated that academic mentoring and advising were important to success. Alumni rated advising as either extremely important or important. The years of advising while an undergraduate student is vitally important in guiding students with classes, jobs, and future careers. The personal aspects and professional guidance given by professors make for the most successful advising of undergraduate pre-veterinary students.

\section{Recommendations}

There are several areas for possible improvement of pre-veterinary undergraduate curriculum based on survey results. The importance of communication development was valued by undergraduates and alumni alike. The inclusion of a communications course or experience tailored to the animal science profession could be beneficial to student success. One option could be to include communications components throughout the curriculum in existing animal science courses (this could include adding more oral and written assignments in the animal science courses). Within the undergraduate curriculum, 
continuing to focus on the core courses that the alumni deemed as important to success, while offering the aid that students need will be the most beneficial to helping them succeed. This could include widening tutoring availability within these important courses, added group projects to enhance teamwork skills, and continually improving the individual mentoring that occurs between students and faculty. Advising and mentoring is a vital step in helping to develop professionals. These small changes and additions can allow students to go from an understanding of their steps to success to walking and achieving their own success within the veterinary profession.

\section{Areas for Future Research}

There are several areas to expand upon for future research studies. The current project was limited to one program and limited responses were obtained from alumni. The study could be expanded to other universities that have similar programs. Future areas to add to this project would be surveying freshman within high schools. Students are preparing much earlier for their career goals and determining traits early on can be helpful for developing precollege programs directed towards student success in the veterinary sciences. This would allow an overlay of the educational flow for students within high school, college, and CVMs to determine the perceptional changes that occur within these educational ranges. Understanding perceptions of high school students can allow for schools to begin preparing their students for future career success by enrolling students in courses and experiences set up for their future career goals.

\section{References}

AAVMC Notes. (2021). VMCAS Applicant Numbers Soar 19 Percent Year Over Year. Journal of Veterinary Medical Education, 48(1), iv-vi February17, 2021.

Annual Data Report 2018-2019 (Rep.). (n.d.). Association of American Veterinary Medical Colleges. Retrieved from https://www.aavmc.org/assets/Site_18/files/Data/2019 AAVMC Annual Data Report (ID100175).pdf

Association of American Veterinary Medical Colleges, \& Dabdub, D. L. (Eds.). (2020). Veterinary Medical School Admission Requirements (VMSAR): Preparing, Applying, and Succeeding, 2020 Edition for 2021 Matriculation. Purdue University Press. https://doi.org/10.2307/j.ctv15wxqdp

Association of American Veterinary Medical Colleges. (2020). What to know before you apply. $\quad$ Retrieved March 20, 2021, from htps://www.aavmc.org/becoming-a-veterinarian/what-to-know-before-you-apply/

Crowe, J. A. (2021). Creating a Departmental Climate that Increases a Student's Sense of Belonging, Perceived Faculty Support, and Satisfaction with the Major. Innov High Educ., 46, 95-109 https://doi.org/10.1007/s10755-020-09530-w

Data USA. (2021). Veterinarians. Retrieved from https://datausa.io/profile/soc/veterinarians\#demographics 


\section{Macrothink}

Journal of Agricultural Studies

ISSN 2166-0379

2021, Vol. 9, No. 4

Green, W., Watson, S., Kennedy, G., Miceli, C., \& Taboada, J. (2006). Forecasting veterinary student admission probabilities for undergraduate student profiles. J of Vet Med Educ., 33, 441-46.

Haldane, S., Hinchcliff, K., Mansell, P., \& Baik, C. (2017). Expectations of Graduate Communication Skills in Professional Veterinary Practice. Journal of veterinary medical education, 44(2), 268-279. https://doi.org/10.3138/jvme.1215-193R

Holladay, S. D., Gogal, R. M., Moore, P. C., Tuckfield, R. C., Burgess, B. A., \& Brown, S. A. (2020). Predictive value of veterinary student application data for class rank at end of year 1. Veterinary Sciences, 7(3), 120. http://dx.doi.org/10.3390/vetsci7030120

Kinnison, T., May S. A., \& Guile, D. (2014). Inter-professional practice: from veterinarian to the veterinary team. $J$ Vet Med Education, 41(2), 172-178. https://doi.org/10.3138/jvme.0713-095R2.

Rauch, M, Wissing, S, Tipold, A, \& Kleinsorgen, C. (2021). Interpersonal survey on communication skills in veterinary and veterinary-related education in Germany. BMC Medical Education, 21, 516. https://doi.org/10.1186/s12909-021-02938-8

Trivedi, S., Jessica, C., Clark, M., \& Todd, S. (2021). Veterinary Professions Advising Center: an innovative approach to preveterinary advising for Animal Science students, Translational Animal Science, 5(2), April, txab064. https://doi.org/10.1093/tas/txab064

VIN Foundation (2019). What experience do I need for veterinary school? Retrieved March 21, 2021,from https://vetschoolbound.org/experience-need-veterinary-school/

\section{Copyright Disclaimer}

Copyright for this article is retained by the author(s), with first publication rights granted to the journal.

This is an open-access article distributed under the terms and conditions of the Creative Commons Attribution license (http://creativecommons.org/licenses/by/4.0/). 